\title{
Machado-Joseph Disease: from first descriptions to new perspectives
}

\author{
Conceição Bettencourt ${ }^{1,2,3^{*}}$ and Manuela Lima ${ }^{1,2}$
}

\begin{abstract}
Machado-Joseph Disease (MJD), also known as spinocerebellar ataxia type 3 (SCA3), represents the most common form of SCA worldwide. MJD is an autosomal dominant neurodegenerative disorder of late onset, involving predominantly the cerebellar, pyramidal, extrapyramidal, motor neuron and oculomotor systems; although sharing features with other SCAs, the identification of minor, but more specific signs, facilitates its differential diagnosis. MJD presents strong phenotypic heterogeneity, which has justified the classification of patients into three main clinical types. Main pathological lesions are observed in the spinocerebellar system, as well as in the cerebellar dentate nucleus. MJD's causative mutation consists in an expansion of an unstable CAG tract in exon 10 of the ATXN3 gene, located at 14q32.1. Haplotype-based studies have suggested that two main founder mutations may explain the present global distribution of the disease; the ancestral haplotype is of Asian origin, and has an estimated age of around 5,800 years, while the second mutational event has occurred about 1,400 years ago. The ATXN3 gene encodes for ataxin-3, which is ubiquitously expressed in neuronal and non-neuronal tissues, and, among other functions, is thought to participate in cellular protein quality control pathways. Mutated ATXN3 alleles consensually present about 61 to 87 CAG repeats, resulting in an expanded polyglutamine tract in ataxin-3. This altered protein gains a neurotoxic function, through yet unclear mechanisms. Clinical variability of MJD is only partially explained by the size of the CAG tract, which leaves a residual variance that should be explained by still unknown additional factors. Several genetic tests are available for MJD, and Genetic Counseling Programs have been created to better assist the affected families, namely on what concerns the possibility of pre-symptomatic testing. The main goal of this review was to bring together updated knowledge on MJD, covering several aspects from its initial descriptions and clinical presentation, through the discovery of the causative mutation, its origin and dispersion, as well as molecular genetics aspects considered essential for a better understanding of its neuropathology. Issues related with molecular testing and Genetic Counseling, as well as recent progresses and perspectives on genetic therapy, are also addressed.
\end{abstract}

Keywords: Ataxin-3, ATXN3 gene, CAG repeats, Polyglutamine disorders, SCA3

\section{Introduction}

Spinocerebellar ataxias (SCAs) are autosomal dominant inherited ataxias, which constitute a heterogeneous group of typically late-onset, progressive, and often fatal neurodegenerative disorders, characterized by progressive cerebellar dysfunction, variably associated with other symptoms of the central and peripheral nervous systems [1-3]. Nearly 30 subtypes of SCAs have been described, and based on the nature of the underlying causative

\footnotetext{
* Correspondence: mcbettencourt@uac.pt

${ }^{1}$ Center of Research in Natural Resources (CIRN) and Department of Biology,

University of the Azores, Ponta Delgada, Portugal

Full list of author information is available at the end of the article
}

mutations, these subtypes can be divided into three major categories: 1) "polyglutamine" ataxias, caused by CAG repeat expansions that encode a pure repeat of the amino acid glutamine in the corresponding protein; 2) non-coding repeat ataxias, caused by repeat expansions falling outside of the protein-coding region of the respective disease genes; and 3) ataxias caused by conventional mutations in specific genes (deletion, missense, nonsense, and splice site mutations) [1]. The focus of this review, Machado-Joseph disease (MJD; MIM \#109150) [4], also known as spinocerebellar ataxia type 3 (SCA3) [5], belongs to the first of the above cited categories [6]. Several alternative designations have been given to this

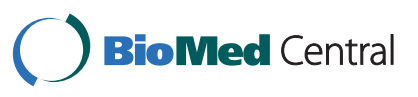


disorder, namely "Machado disease" [7], "nigro-spinodentatal degeneration with nuclear ophthalmoplegia" [8], "autosomal dominant striatonigral degeneration" [9] and "Azorean disease of the nervous system" [10]. Presently, the most widely used designations are MJD and SCA3.

\section{Epidemiology}

Globally, SCAs are considered rare disorders, with prevalence estimates varying from 0.3 to 2.0 per 100,000 [11]. MJD is presently considered the most common form of SCA worldwide [12]. The availability of a molecular test has allowed a thorough identification of cases, changing the initial geographic distribution pattern of MJD, initially thought to be related with the Portuguese discoveries and currently known to be present in many ethnic backgrounds [12], with strong geographic variation.

Among SCAs, the relative frequency of MJD is higher in countries such as Brazil (69-92\%) [13,14], Portugal (58-74\%) [15,16], Singapore (53\%) [17], China (48-49\%) $[18,19]$, the Netherlands (44\%) [11], Germany (42\%) [20], and Japan (28-63\%) [21,22]. It is relatively less frequent in Canada (24\%) [23], United States (21\%) [24], Mexico (12\%) [25], Australia (12\%) [26], and India (5-14\%) $[27,28]$, and it is considered as relatively rare in South Africa (4\%) [29] and Italy (1\%) [30].

Even within each country the geographic distribution pattern of MJD is not homogeneous. Although constituting the most prevalent subtype of SCA, in Portugal, for example, MJD is relatively rare in the mainland $(1 / 100,000)$ [31], with few exceptions such as a small area of the Tagus River Valley $(1 / 1,000)$ [32], but highly prevalent in the Azores Islands, where the highest worldwide prevalence occurs in Flores Island (1/239) [33].

\section{Clinical Presentation}

MJD is a multisystem neurodegenerative disorder involving predominantly the cerebellar, pyramidal, extrapyramidal, motor neuron and oculomotor systems. A clinical diagnosis is suggested in individuals with progressive cerebellar ataxia and pyramidal signs, associated with a complex clinical picture extending from extrapyramidal signs to peripheral amyotrophy [34]. Minor, but more specific, features such as external progressive ophthalmoplegia (EPO), dystonia, intention fasciculation-like movements of facial and lingual muscles, as well as bulging eyes, may also be of major importance for the clinical diagnosis of MJD [34]. The mean age at onset is around 40 years, with extremes of 4 [35] and 70 years [31], and a mean survival time of 21 years (ranging from 7 to 29 years) [31,36]. Gait ataxia and diplopia are reported as first symptoms in $92.4 \%$ and $7.6 \%$ of cases, respectively [31].

MJD is characterized by a high degree of pleomorphism, not only in the variability in the age at onset, but also in the neurological signs presented by different patients as well as in the resulting degree of incapacity. The striking clinical heterogeneity characteristic of this disease is demonstrated by the history of its initial description. In fact, the observation of three families of Azorean ancestry (Machado, Thomas and Joseph), living in the United States of America, by three distinct groups of researchers, led to the initial description, during the 1970s, of three apparently independent diseases [7-9]. The subsequent identification of several Portuguese families living both in the Azores Islands and in the mainland of Portugal, within some of which were patients covering the three forms described, led to the unification of the disease. MJD was afterward considered as a single genetic entity, with variable phenotypic expression [4]. The marked clinical heterogeneity and the progressive nature of MJD rendered its clinical classification difficult. Coutinho and Andrade [4] systematized the disease phenotypes into three main clinical types. They observed that almost every patient presents with cerebellar signs and EPO, associated with pyramidal signs in variable degrees. Clinical types could, therefore, be distinguished on the basis of the presence/absence of important extrapyramidal signs, and the presence/absence of peripheral signs. Type 1 ("type Joseph") is characterized by an early onset (mean of 24.3 years) and a rapid progression of symptoms, which together with cerebellar ataxia and EPO include marked pyramidal and extrapyramidal signs (such as dystonia). Type 2 ("type Thomas") corresponds to presentations with an intermediate onset (mean of 40.5 years), cerebellar ataxia and EPO, with or without pyramidal sings. When present, the extrapyramidal and peripheral signs are tenuous. Patients with type 2 features may maintain these for long periods or evolve (5 to 10 years later) to type 1 or type 3 , by the manifestation of important extrapyramidal or peripheral signs, respectively. Type 3 ("type Machado") presents a later onset (mean of 46.8 years) and is characterized by cerebellar ataxia and EPO, associated with peripheral alterations, with or without slight pyramidal and extrapyramidal signs [31]. As previously mentioned, these three clinical types can occasionally be present in the same family. Additionally, some authors consider as type 4 a rare presentation with parkinsonian features, with mild cerebellar deficits and a distal motor sensory neuropathy or amyotrophy [37]. Furthermore, Sakai and Kawakami [38] observed two siblings that presented spastic paraplegia without cerebellar ataxia and proposed the existence of a fifth type for MJD.

Pathological studies reveal, in most cases, that the brain weight of MJD patients is considerably reduced, in comparison to individuals without medical history of neurological or psychiatric diseases [39-42]. Furthermore, depigmentation of the substantia nigra, and atrophy of the cerebellum, pons, and medulla oblongata, as well as 
of the cranial nerves III to XII, has been consistently observed in MJD brains [40,43-45]. Neuropathological studies typically reveal neuronal loss in the cerebellar dentate nucleus, pons, substantia nigra, thalamus, globus pallidus, anterior horn cells and Clarke's column in the spinal cord, vestibular nucleus, many cranial motor nuclei, and other brainstem nuclei [39-41,46-55]. Such studies indicate that central nervous white matter lesions are confined to the medial lemniscus, spinocerebellar tracts and dorsal columns [39,40,45,51-55]. Although the inferior olive, as well as the cerebellar cortical neurons, were thought to be typically spared $[31,41,56]$, conflicting results have been reported [39,40,51-53,55].

Magnetic resonance imaging (MRI) has been considered a useful tool in the study and in the diagnostic process of MJD [42,57-61]. Volumetric analyses performed on MRI of MJD patients have previously demonstrated atrophy of the cerebellum, brainstem, caudate nuclei, and putamen [62]. MR spectroscopy studies have also shown abnormalities in apparently normal deep white matter [63]. A recent study [61], using MRI-Texture analysis, showed significant differences among images texture of the caudate nucleus, thalamus, and putamen between patients and a control group, showing that this could constitute a promising tool for the detection and quantification of cerebral tissue areas affected in MJD.

\section{Molecular Genetics And Pathogenesis}

The disease locus was first mapped to the long arm of chromosome 14 (14q24.3-q32) by Takiyama et al. in 1993 [64]. In 1994, Kawaguchi et al. [65] showed that an expansion of a CAG repeat motif at the MJD1 gene, mapped to $14 \mathrm{q} 32.1$, was present in all affected individuals of a pathologically confirmed MJD family. The genomic structure of the $M J D$ gene was published seven years later [66]. The gene was found to span about $48 \mathrm{~kb}$ and was described as containing 11 exons, with the (CAG) tract located at the exon 10 (Figure 1). Two additional exons, 6a and 9a, were recently described (Figure 1) [67]. Currently, the official name of the gene is ATXN3, but other aliases, such as $M J D$ and $M J D 1$, are still in use.

Consensually, wild-type alleles range from 12 to 44 CAG repeats, whereas well established limits of expanded alleles comprise from 61 to 87 repeat units [32]. Intermediate size alleles are rare, but there are a few reports of disease associated alleles containing 56, 55, 54, 53, 51, and 45 CAG repeats [68-73]. On the other hand, an allele with 51 repeats was described, in a Portuguese family, apparently not associated with the disease [32]. Thus, there is the possibility that low penetrance alleles, of intermediate size, which are relatively frequent in other polyglutamine disorders, namely in Huntington's disease (HD) [74], may also occur in MJD.
The ATXN3 gene encodes for a protein named ataxin-3, which was originally reported to be composed of 339 amino acid residues plus a variable number of glutamine repeats, with an estimated molecular weight of $40-43 \mathrm{kDa}$ for normal individuals [65]. Northern blot analysis showed that the ATXN3 mRNA is ubiquitously transcribed in neuronal and non-neuronal human tissues [66]. Moreover, such ubiquitous expression was also demonstrated, by immunohistochemical studies, at the protein level, which is expressed not only in the brain but also throughout the body, existing both in the cytoplasm and the nucleus of various cell types. However, in neurons, ataxin-3 is predominantly a cytoplasmic protein [50]. Given its ubiquitous pattern, cellular expression of the disease gene is not itself sufficient to explain selective neuronal degeneration, suggesting that other cell-specific factors are involved in the restricted neuropathology observed in MJD [50].

At least four different species of ATXN3 transcripts with different sizes, estimated in approximately 1.4, 1.8, 4.5 , and $7.5 \mathrm{~kb}$, were reported by Northern blot analysis [66]. These different mRNA species are thought to result from differential splicing of, at least, exons 10 and 11 of ATXN3 gene, and alternative polyadenylation of exon 11. From sequence analysis of cDNA clones, Ichikawa et al. [66] reported the existence of a minimum of five MJD gene products (MJD1a; pMJD1-1; pMJD2-1; pMJD5-1; H2). The MJD1a was first described by Kawaguchi et al. [65]. Three additional transcripts (pMJD1-1; pMJD2-1; pMJD5-1) that differ from the MJD1a, mainly at the C-terminal, were then reported by Goto et al. [75]. Finally, Ichikawa et al. [66] described the variant $\mathrm{H} 2$ as having an amino acid sequence identical to the one of pMJD1-1, except for a gap of 55 amino acids, which results from the skipping of exon 2 by alternative splicing. Additional ATXN3 splicing variants have been deposited in databases, such as ASPicDB [76]. Recently, a large number of alternative splicing variants $(n=56)$ generated by four types of splicing events (exon skipping, new exons, usage of alternative $5^{\prime}$ or $3^{\prime}$ splice sites), occurring in a simple or combined way, were described for the ATXN3 gene [67]. Fifty of those had not been previously described (either in the literature or in databases), and are thought to constitute new alternative splicing variants for this gene. This suggests that alternative splicing may be an important mechanism regulating ataxin-3 diversity, and clearly indicates that there are mechanisms generating variability, beyond genomic DNA.

Ataxin-3 belongs to the family of cysteine proteases. Structurally, it is composed of a globular N-terminal Josephin domain (amino acid residues 1-182 in the human protein) [77] with a papain-like fold, combined with a more flexible $\mathrm{C}$-terminal tail that contains 2 or 3 ubiquitin 


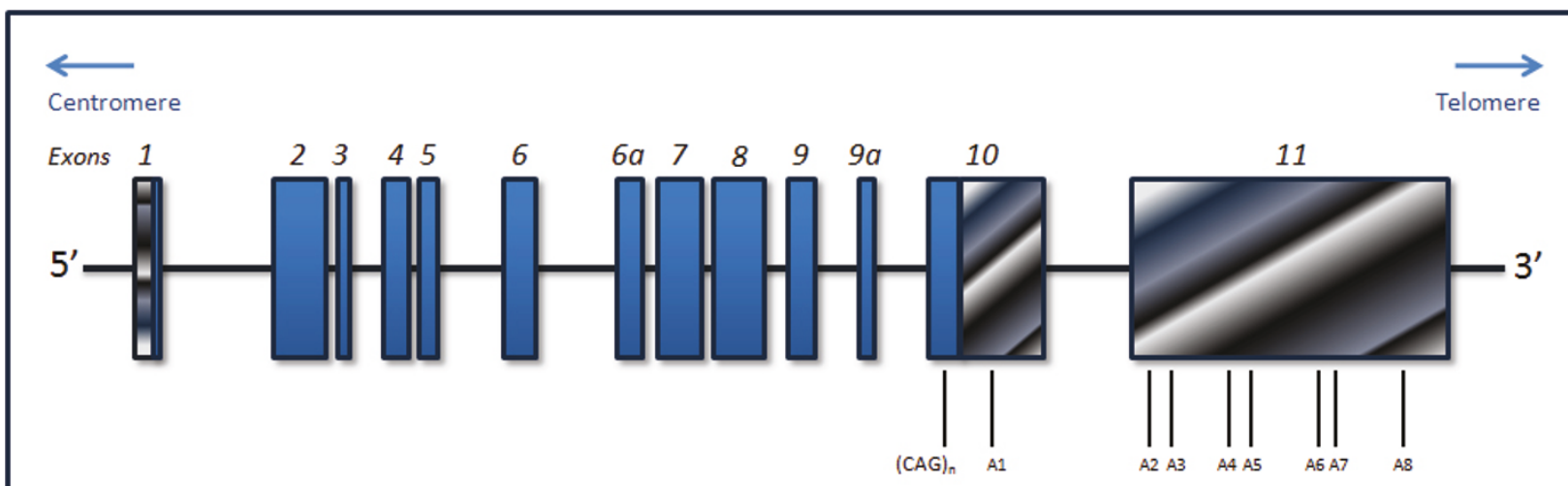

Figure 1 Schematic representation of the ATXN3 gene structure. Exons are numbered from 1 to 11 and are presented as boxes. Filled blue boxes indicate the coding regions, hatched horizontal boxes represent the 5'-untranslated region (UTR), and hatched diagonal boxes correspond to the $3^{\prime}-$ UTR. The location of the polymorphic $(C A G)_{n}$ tract is indicated. Polyadenylation consensus sequences are marked from A1 to A8.

interaction motifs (UIMs) and the polymorphic polyglutamine tract (polyQ tract) [78]. The Josephin domain (JD) contains highly conserved amino acids, reminiscent of the catalytic residues of a deubiquitinating cysteine protease. The catalytic pocket consists of a glutamine (Q9) and a cysteine (C14) residue located in the $\mathrm{N}$-terminal part of JD, and of a histidine (H119) and an asparagine (N134) in the JD C-terminal part. The cysteine, the histidine, and the asparagine constitute the catalytic triad characteristic of cysteine proteases [79]. Although the physiologic role of ataxin-3 is still unclear, it has been proposed that the wildtype form acts as a deubiquitinating enzyme (DUB) in the ubiquitin-proteasome pathway $[80,81]$. Moreover, it has been established that ataxin- 3 can be directly activated by ubiquitination [82]. Additionally, ataxin-3 has been described having a deneddylase activity [83]. Its involvement in transcriptional regulation has also been proposed $[80,84]$. Furthermore, the participation of ataxin-3 in the regulation of aggresome formation, as well as in the degradation of proteins sent from the endoplasmic reticulum has been described [85]. Taken together with its enzymatic properties, these facts suggest that ataxin- 3 normally participates in protein quality control pathways in the cell $[46,82]$. Recently, it has been suggested that this protein may also be important for a correct cytoskeletal organization [86], as well as for muscle differentiation through the regulation of the integrin signaling transduction pathway [87]. In its mutated form, when the polyQ tract reaches the pathological threshold (about 50 glutamine residues), the protein is thought to gain a neurotoxic function that, as a consequence, leads to selective neuronal cell death through a not fully understood process $[50,88]$.

From the recently described ATXN3 alternative splicing variants, 20 are thought to encode distinct ataxin- 3 isoforms. Although by the analysis of their domain composition, it can be predicted that some may play a protective role while others may lead to increased toxicity [67], their effective role is still unknown. It also remains unexplored if differential expression of the distinct ataxin-3 isoforms could be involved in the specificity of neuronal vulnerability. Nevertheless, it has been observed that the subcellular distribution of ataxin-3 (independently of its isoform) differs in diseased brain versus normal brain. While normally it is a predominantly cytoplasmic protein in neurons (as mentioned earlier), ataxin- 3 becomes concentrated in the nucleus of neurons during disease. Moreover, in many brain regions, ataxin-3 forms intranuclear inclusions [89]. These neuronal inclusions, which are also found in other polyglutamine disorders, are heavily ubiquitinated and contain certain heat shock molecular chaperones and proteasomal subunits, suggesting that they are repositories for aberrantly folded, aggregated proteins [90]. The presence of ubiquitinated neuronal intranuclear inclusions (NIIs) has thus been recognized as a neuropathologic hallmark of these diseases, although the significance of NIIs in the pathogenesis remains a matter of controversy [45]. Relatively recent neuropathologic studies [91,92] suggest that inclusions are not directly pathogenic structures and may rather be the byproduct of neuronal efforts to wall off abnormal proteins in a nontoxic manner.

\section{Origins And Mechanisms Of Mutation}

Two large studies focus the worldwide origin of the MJD mutation [93,94]. Gaspar et al. [93], by haplotype analyses of three intragenic SNPs $\left(\underline{A}^{669} \mathrm{TG} / \underline{G}^{669} \mathrm{TG}\right.$, $\underline{C}^{987} \mathrm{GG} / \underline{G}^{987} \mathrm{GG}$, and TA$\left.\underline{A}^{1118} / \mathrm{TA} \underline{C}^{11 \overline{18}}\right)$, found that two (ACA and GGC), out of the four observed MJD haplotypes, were present in $94 \%$ of the MJD families. For the families of Azorean extraction, these two main haplotypes were found, presenting a distribution specific to the island of origin: ACA was observed in the families from 
Flores Island, while GGC was found in the families from São Miguel Island. These results indicated that two distinct mutational events accounted for the presence of MJD in the Azorean Islands and in families of Azorean extraction, a fact previously evidenced by studies based on the genealogical reconstruction of affected families $[95,96]$. In Portugal mainland, both haplotypes were also found. Worldwide, $72 \%$ of the families share the ACA, further supporting the idea of few mutational events. Based on haplotype analyses, it has been suggested that two main founder mutations may explain the present global geographic distribution of MJD [93,94]. In opposition to the Portuguese/Azorean origin that was proposed at the time of the initial descriptions of the disease, an Asian origin was recently suggested by Martins et al. [94]. Their work, which aimed to determine the origins, age, and spread of the two main mutational events, through more extensive haplotype analyses, revealed that the worldwide spread lineage TTACAC reaches its highest diversity in Asia (Japanese population). An ancestral STR-based haplotype was identified in that population, and a postneolithic mutation with about 5,774 $\pm 1,116$ years old was suggested. More recent introductions of this lineage are reported for North America, Germany, France, Portugal, and Brazil. A second mutational event, in the GTGGCA lineage, is thought to be more recent (about $1,416 \pm 434$ years old). The matter of its origin is more controversial, but its dispersion may be mainly explained by recent Portuguese emigration [94].

The existence of repeat instability has been reported for mutated MJD alleles, similarly to what has been described for the group of "polyglutamine" disorders or for the even larger group of triplet repeat disorders, in which MJD is included [97]. However, the underlying mutational process that allows for alleles in the normal range to, ultimately, expand to pathological size is not clearly understood. Lima et al. [98], on a study of nearly 2,000 chromosomes of the Portuguese population, found an allelic distribution biased towards the smaller alleles, not supporting, therefore, the idea that the larger alleles could constitute a reservoir from where expanded alleles could be continuously generated. Analysis of the distribution of the CAG repeat length frequency within the four most frequent wild-type lineages (defined by intragenic polymorphisms) supports the existence of a multistep mutation mechanism on the basis of the evolution of ATXN3 alleles, either by gene conversion or DNA slippage [99].

\section{Inheritance And Genotype-Phenotype Correlations}

MJD displays an autosomal dominant pattern. Therefore, each sibling of an affected individual, or an asymptomatic carrier, has an a priori risk of $50 \%$ of being itself a carrier, with both genders having equal probabilities of receiving/ transmitting the mutated allele and expressing the disease. Very few cases (2\%) of non-penetrance are known [100], and therefore, in the context of genetic counseling (GC), MJD is considered fully penetrant. However, given the fact that MJD penetrance displays an age-dependent pattern (table 1), the probability of being a mutation carrier, and consequently the a posteriori risk, diminishes with age in asymptomatic individuals, reaching approximately zero at the age of 70 years [33].

An inverse correlation is found between the size of the CAG repeat tract at the expanded alleles (and consequently the size of the polyQ tract) and the age at onset of the disease. Depending on the series of patients in study, it accounts from $50 \%$ to nearly $75 \%$ of variation in the age of appearance of the first symptoms [101,102]. A similar inverse correlation has also been described at the mRNA level [103]. Furthermore, the size of the expanded alleles has also been associated with the frequency of other clinical features, such as pseudoexophthalmos and pyramidal signs, which are more frequent in subjects with larger repeats [104]. Moreover, a gene dosage effect seems to be present in MJD, since homozygosity aggravates the clinical phenotype, with a more severe progression and an early age at onset in subjects carrying the expanded allele in both chromosomes $[35,105,106]$. Anticipation has been reported for MJD and other triplet repeat (TR) diseases $[97,107]$. Such phenomenon implicates more severe phenotypes and/or earlier ages at onset in successive generations. This can be explained by the dynamic process of mutation underlying TR diseases, which involves intergenerational instability. Normal alleles are usually transmitted to the offspring without modifications [108], while most expanded alleles are unstable upon transmission due to germinal instability, especially in male meiosis [109]. The observed tendency of expanded alleles to further increase the size of its repeat tract, in successive generations, is thought to be the genetic cause of anticipation [97].

Besides the $(\mathrm{CAG})_{\mathrm{n}}$ tract size, familial factors that may increase the explanation of the onset variance have been described [31,110,111]. Although the influence of environmental factors cannot be excluded, the fact that variability within families is lower than the one observed between families supports the contribution of other genetic factors, namely modifier genes, to the remaining phenotypic variance. Modifier genes of the MJD phenotype have been, so far, searched using a candidate-gene approach. Jardim et al. [112] analyzed the polymorphic CAG repeats in other repeat loci (SCA2, SCA6 and DRPLA), and concluded that the CAG repeat length of the larger SCA2 allele (22-23 CAG repeats) is associated with the severity of fasciculations. No associations were found with the remaining phenotypic features, namely age of onset, anticipation, and clinical types. An exhaustive search for MJD 
Table 1 Age-dependent risk for asymptomatic individuals with an MJD a priori risk of 50\% (data from Bettencourt et al. [33])

\begin{tabular}{ccc}
\hline Age in years & Probability of detectable gene expression & Probability of heterozygous if unaffected \\
\hline 10 & 0.02 & 0.50 \\
\hline 20 & 0.03 & 0.49 \\
\hline 30 & 0.22 & 0.44 \\
\hline 40 & 0.53 & 0.32 \\
\hline 50 & 0.80 & 0.17 \\
\hline 60 & 0.96 & 0.04 \\
\hline 70 & 1.00 & $\sim 0$ \\
\hline
\end{tabular}

modifier genes remains difficult to perform, among other aspects, because of constrains in sample size.

\section{Genetic Testing And Counseling}

In the early stages of the disease, when minor but specific signs are missing, when the disease seems sporadic, when it is present in patients belonging to small family units, or when the ethnic or geographic background of the patient is thought to be unusual for this disease, a clinical diagnosis of MJD may not be simple to establish. The identification of MJD's causative gene allowed the direct detection of the mutation, thus enabling the molecular diagnosis of the disease [101]. Furthermore, it allowed worldwide molecular studies about MJD, leading, as previously referred, to a distribution of cases that was clearly different from the initial scenario, obtained exclusively by clinical criteria [113]. Predictive Testing (PT) also became possible for at-risk family members, providing an accurate confirmation of the carrier/non-carrier status in asymptomatic individuals. Targeted mutation analysis of the ATXN3 gene is also used for the Prenatal Diagnosis (PND) of this disease [114]. However, since a positive result for the MJD mutation raises issues concerning the termination of the pregnancy, several psychological and ethic questions emerge. An alternative for PND, the Preimplantation Genetic Diagnosis (PGD) is also presently available [115]. Levels of adherence to these genetic tests remain to be determined at a large scale. In the Azores Islands, participation in PT was estimated as being around $21 \%$. If, however, only the small Azorean island of Flores is considered, the adherence levels reach nearly 36\% [116]. In another small community, the rural region of the Tagus Valley (Portugal mainland), adherence levels to PT program were also high (over 80\%) [117]. These high adherence levels in small, isolated communities raise interesting issues, since in such populations genetic diseases can represent a source of stigmatization to the affected families [116]. Therefore, a careful intervention regarding genetic tests, adapted to each specific context, is mandatory.

There is a current lack of effective therapeutics for MJD (see "Patients Management"). Therefore, it is crucial to provide adequate $\mathrm{GC}$ to patients and their families, providing information concerning the nature of the disease, the current lack of disease treatment, the risk for other family members as well as the availability of molecular tests, previously mentioned. PT, PND and PGD are offered within the frame of a GC Program. As an example, the Portuguese GC Program, which was based mainly on the experience with HD, aims to provide to at-risk adults the access to the genetic information that can reduce the uncertainty about their genetic status. Another of its goals is to provide the necessary psychological support to allow the proper adaptation to the test results [118]. Candidates for the MJD PT Program have been defined as those: a) at 50\% risk and wishing to receive genetic information; b) over 18 years old and capable of providing informed consent; c) with a molecularly confirmed familial history of MJD; and d) asymptomatic for the disease [118].

Teams offering GC to MJD families must provide adequate and comprehensible information concerning the genetics of MJD to the affected families. A study with Azorean MJD families, conducted prior to the application of the PT in this population [119] showed that a large percentage of individuals were unable to comprehend the notion of "pre-symptomatic carrier" and, therefore, could not quantify the objective risk of inheriting/transmitting the disease.

Analysis of the motives for undertaking the PT and of the impact of the test on the psychological well-being of those tested is of major importance for the design of effective GC programs. Leite et al. [120] developed a Psychological General Well-Being Schedule, to evaluate psychological wellbeing in persons coming for MJD pre-symptomatic testing in comparison with normal population. These authors observed that, contrarily to what was expected, individuals at-risk presented higher psychological well-being indicators than the control group. Two possible explanations were suggested by Leite et al.[120] to justify such results: a) the group of individuals at-risk has a defensive and denial attitude, and/or b) the group of individuals at-risk is psychologically more resilient, which may have motivated their 
adhesion to pre-symptomatic testing, through their own self-selection. Gonzalez et al. [116], in a short-term study of the impact of PT in the Azores, found no differences in the mean scores of depression or anxiety before and one year after the PT. These authors concluded that the disclosure of the genetic status did not decrease the psychological well-being of the individuals that undertook testing. Accordingly, the study by Rolin et al. [121], which compared data obtained before and 3 to 6 months after the disclosure of genetic testing results, showed no significant changes in well-being and specific distress of PT applicants, both in the individuals identified as carriers and non-carriers. A similar result to what was observed in another study in Japan [122]. Furthermore, it has been shown that the anxiety levels are reduced in those who received a noncarrier result [122,123].

With the advent of pre-symptomatic testing, several laboratory difficulties emerged, and improvements in the diagnosis of MJD had to be made. The first problem was the occurrence of intermediate size alleles, for which it is still not possible to determine whether they are associated with a phenotype or not [32]. To minimize this constrain, clinical and molecular analysis, including the determination of CAG repeat length and the establishment of intragenic haplotypes, of large pedigrees of the affected families, is essential. Furthermore, the study of the healthy population, from the same region, to assess the distribution of the normal $(C A G)_{n}$ length in that specific population, may also be important [98]. The second problem relied on the presence of homoallelism, i.e., homozygosity for two normal alleles with exactly the same (CAG) length (about $10 \%$ of all test results). This was solved by studying intragenic polymorphisms, which allowed the distinction of the two normal chromosomes. Furthermore, using a new Southern blot based method, the possibility of existence of an expanded allele in the presumed homoallelic individuals can also be excluded [32]. There are limitations in sizing precision of the CAG repeats due to the existence of somatic mosaicism [124], which originates differences in $(\mathrm{CAG})_{\mathrm{n}}$ length among subpopulations of lymphocytes as well as between lymphocytes (where length is usually measured) and central nervous system cells. However, for molecular diagnosis purposes, an error of \pm 1 CAG repeat is considered as acceptable [32].

\section{Patients Management And New Perspectives In Treatment}

On what concerns disease treatment, effective pharmacologic approaches for the MJD treatment as well as for other SCAs are still lacking or inadequate. Symptomatic pharmacologic therapeutics are used to alleviate some of the clinical signs, namely spasticity $[125,126]$, parkinsonism $[127,128]$, dystonia $[129,130]$, and muscle cramps
[131]. Several clinical trials have also been carried out. The initial double-blind, placebo-controlled, clinical trials were performed with sulfamethoxazole and trimethoprim, in a small number of MJD patients [126,132-134]. From those studies, encouraging results were obtained in terms of lessened spasticity, improvements in walkerassisted gait [132], improvements in contrast sensitivity [133], mild improvements of hyperreflexia of knee jerks and of rigospasticity of the legs [134], beneficial effects on gait and coordination [126]. However, in a larger study, also double-blind and placebo-controlled, trimethoprim-sulfamethoxazole therapy showed no significant effects [135]. The treatment of MJD patients with fluoxetine, failed to improve motor abilities [136]. On the other hand, the use of taltirelin hydrate, was shown to be effective on the ataxic speech of patients with MJD [137]. The treatment with tandospirone pointed for a reduction of ataxia and of depression levels, alleviation of insomnia and leg pain, suggesting that this is a useful drug for these symptoms in patients with MJD [138]. Another trial [139] involved the clinical response of lamotrigine (LTG) on MJD patients with early truncal ataxia and the effect of LTG on the alteration of ataxin-3 expression in the transformed MJD lymphoblastoid cells. Results from this trial indicated that LTG may have significant benefits in relief of gait disturbance in MJD patients with early ataxia, which may be related to the decreased expression of mutant ataxin-3. Notwithstanding some promising results, all these trials were carried out in a small number of patients ( 1 to 22 patients) and over short periods of time. Studies with a length, design and sample size to provide adequate power to detect meaningful effects should be carefully planned on the basis of underlying basic science before undergoing trials [140].

In addition to pharmacological approaches, physiotherapy may help the patients to cope with the disability associated with gait problems [141]. Physical aids, such as walkers and wheelchairs, can assist the patients in their everyday activities. Moreover, regular speech therapy evaluation for dysarthria and dysphagia as well as occupational therapy may also help patients [141].

Recent advances have been made in the field of genetic therapy. The use of small interfering RNA (siRNA) has been taken as a promising approach for treating autosomal dominant disorders. Although the mouse [142] and Caenorhabditis elegans [143] knockout models for ataxin-3 were viable and displayed no overt phenotype, suggesting that ataxin-3 is a non-essential protein, in both cases its importance as a DUB enzyme was confirmed. Nevertheless, there is no correspondent model in humans at our days that could support the hypothesis of ataxin-3 as a non-essential protein. Therefore, discrimination between wild-type and mutant transcripts should be an important point to be addressed in therapeutics 
development, in order to preserve wild-type ataxin-3 expression and function. Strategies based on the presence of a single nucleotide polymorphism (SNP) have been proposed to ensure discrimination between wild-type and mutant transcripts [144]. After the understanding of the worldwide distribution of the MJD haplotypes $[93,94]$, the intragenic SNP $\underline{G}^{987} \mathrm{GG} / \underline{C}^{987} \mathrm{GG}$ at the 3 ' end of the CAG tract, which variant $\mathrm{C}$ is present in more than $70 \%$ of the expanded alleles, seemed to bring good perspectives to the possibility of discriminating between wild-type and mutant ATXN3 alleles. Promising results were obtained by Alves et al. [145], who, using siRNA assays targeting that SNP, reached therapeutic efficacy and selectivity in a rat model of MJD. However, transposing this to MJD patients would result inefficient in the case of homozygosis for the $\mathrm{C}$ variant, or in the absence of this variant in the expanded allele. Thus, the search for ATXN3 transcript variation is still imperative for the application of such siRNA approaches. Recently, another strategy for allele-specific silencing of the mutant ATXN3 mRNA was applied [146], via antisense oligomers, that discriminate between the wild-type and the expanded alleles on the basis of the $(C A G)_{n}$ repeat length in cell lines. Much is still needed to transpose those allelespecific silencing strategies to effective treatment of patients, but good perspectives are foreseen in the future.

\section{Acknowledgements \\ This work was supported by the project "Transcriptional variation of the ATXN3 gene as modulator of the clinical heterogeneity in Machado-Joseph disease (MJD)" (PIC/IC/83074/2007, funded by "Fundação para a Ciência e a Tecnologia" - FCT). C.B. is a postdoctoral fellow of FCT [SFRH/BPD/63121/ 2009]. \\ Author details \\ ${ }^{1}$ Center of Research in Natural Resources (CIRN) and Department of Biology, University of the Azores, Ponta Delgada, Portugal. ${ }^{2}$ Institute for Molecular and Cellular Biology (IBMC), University of Porto, Porto, Portugal. ${ }^{3}$ Laboratorio de Biología Molecular, Instituto de Enfermedades Neurológicas de Guadalajara, Fundación Socio-Sanitaria de Castilla-La Mancha, Guadalajara, Spain.}

\section{Authors' contributions}

CB drafted the manuscript. ML revised critically the content of the manuscript. Both authors have read and gave their final approval of the version to be published.

\section{Competing interests}

The authors declare that they have no competing interests.

Received: 7 September 2010 Accepted: 2 June 2011

Published: 2 June 2011

\section{References}

1. Soong BW, Paulson HL: Spinocerebellar ataxias: an update. Curr Opin Neurol 2007, 20(4):438-446.

2. Carlson KM, Andresen JM, Orr HT: Emerging pathogenic pathways in the spinocerebellar ataxias. Curr Opin Genet Dev 2009, 19(3):247-253.

3. Tsuji S, Onodera O, Goto J, Nishizawa M: Sporadic ataxias in Japan-a population-based epidemiological study. Cerebellum 2008, 7(2):189-197.
4. Coutinho P, Andrade C: Autosomal dominant system degeneration in Portuguese families of the Azores Islands. A new genetic disorder involving cerebellar, pyramidal, extrapyramidal and spinal cord motor functions. Neurology 1978, 28(7):703-709.

5. Stevanin G, Le Guern E, Ravise N, Chneiweiss H, Durr A, Cancel G, Vignal A, Boch AL, Ruberg M, Penet $C$, et al: A third locus for autosomal dominant cerebellar ataxia type I maps to chromosome 14q24.3-qter: evidence for the existence of a fourth locus. Am J Hum Genet 1994, 54(1):11-20.

6. Shao J, Diamond Ml: Polyglutamine diseases: emerging concepts in pathogenesis and therapy. Hum Mol Genet 2007, 16(Spec No. 2):R115-123.

7. Nakano KK, Dawson DM, Spence A: Machado disease. A hereditary ataxia in Portuguese emigrants to Massachusetts. Neurology 1972, 22(1):49-55.

8. Woods BT, Schaumburg HH: Nigro-spino-dentatal degeneration with nuclear ophthalmoplegia. A unique and partially treatable clinicopathological entity. J Neurol Sci 1972, 17(2):149-166.

9. Rosenberg RN, Nyhan WL, Bay C, Shore P: Autosomal dominant striatonigral degeneration. A clinical, pathologic, and biochemical study of a new genetic disorder. Neurology 1976, 26(8):703-714.

10. Romanul FC, Fowler HL, Radvany J, Feldman RG, Feingold M: Azorean disease of the nervous system. N Engl J Med 1977, 296(26):1505-1508.

11. van de Warrenburg BP, Sinke RJ, Verschuuren-Bemelmans CC, Scheffer $H$, Brunt ER, Ippel PF, Maat-Kievit JA, Dooijes D, Notermans NC, Lindhout D, et al: Spinocerebellar ataxias in the Netherlands: prevalence and age at onset variance analysis. Neurology 2002, 58(5):702-708.

12. Schols L, Bauer P, Schmidt T, Schulte T, Riess O: Autosomal dominant cerebellar ataxias: clinical features, genetics, and pathogenesis. Lancet Neurol 2004, 3(5):291-304.

13. Teive HA, Munhoz RP, Raskin S, Werneck LC: Spinocerebellar ataxia type 6 in Brazil. Ara Neuropsiquiatr 2008, 66(3B):691-694.

14. Jardim LB, Silveira I, Pereira ML, Ferro A, Alonso I, do Ceu Moreira M, Mendonca P, Ferreirinha F, Sequeiros J, Giugliani R: A survey of spinocerebellar ataxia in South Brazil - 66 new cases with MachadoJoseph disease, SCA7, SCA8, or unidentified disease-causing mutations. J Neurol 2001, 248(10):870-876.

15. Vale J, Bugalho P, Silveira I, Sequeiros J, Guimaraes J, Coutinho P: Autosomal dominant cerebellar ataxia: frequency analysis and clinical characterization of 45 families from Portugal. Eur J Neurol 2010, 17(1):124-8.

16. Silveira I, Coutinho P, Maciel P, Gaspar C, Hayes S, Dias A, Guimaraes J, Loureiro L, Sequeiros J, Rouleau GA: Analysis of SCA1, DRPLA, MJD, SCA2, and SCA6 CAG repeats in 48 Portuguese ataxia families. Am J Med Genet 1998, 81(2):134-138.

17. Zhao Y, Tan EK, Law HY, Yoon CS, Wong MC, Ng I: Prevalence and ethnic differences of autosomal-dominant cerebellar ataxia in Singapore. Clin Genet 2002, 62(6):478-481.

18. Tang B, Liu C, Shen L, Dai H, Pan Q, Jing L, Ouyang S, Xia J: Frequency of SCA1, SCA2, SCA3/MJD, SCA6, SCA7, and DRPLA CAG trinucleotide repeat expansion in patients with hereditary spinocerebellar ataxia from Chinese kindreds. Arch Neurol 2000, 57(4):540-544.

19. Jiang H, Tang BS, Xu B, Zhao GH, Shen L, Tang JG, Li QH, Xia K: Frequency analysis of autosomal dominant spinocerebellar ataxias in mainland Chinese patients and clinical and molecular characterization of spinocerebellar ataxia type 6. Chin Med J (Engl) 2005, 118(10):837-843.

20. Schols L, Amoiridis G, Buttner T, Przuntek H, Epplen JT, Riess O: Autosomal dominant cerebellar ataxia: phenotypic differences in genetically defined subtypes? Ann Neurol 1997, 42(6):924-932.

21. Maruyama H, Izumi Y, Morino H, Oda M, Toji H, Nakamura S, Kawakami H: Difference in disease-free survival curve and regional distribution according to subtype of spinocerebellar ataxia: a study of 1,286 Japanese patients. Am J Med Genet 2002, 114(5):578-583.

22. Shibata-Hamaguchi A, Ishida C, Iwasa K, Yamada M: Prevalence of spinocerebellar degenerations in the Hokuriku district in Japan. Neuroepidemiology 2009, 32(3):176-183.

23. Kraft S, Furtado S, Ranawaya R, Parboosingh J, Bleoo S, McElligott K, Bridge P, Spacey S, Das S, Suchowersky O: Adult onset spinocerebellar ataxia in a Canadian movement disorders clinic. Can J Neurol Sci 2005, 32(4):450-458.

24. Moseley ML, Benzow KA, Schut LI, Bird TD, Gomez CM, Barkhaus PE, Blindauer KA, Labuda M, Pandolfo M, Koob MD, et al: Incidence of dominant spinocerebellar and Friedreich triplet repeats among 361 ataxia families. Neurology 1998, 51(6):1666-1671. 
25. Alonso E, Martinez-Ruano L, De Biase I, Mader C, Ochoa A, Yescas P, Gutierrez R, White M, Ruano L, Fragoso-Benitez M, et al: Distinct distribution of autosomal dominant spinocerebellar ataxia in the Mexican population. Mov Disord 2007, 22(7):1050-1053.

26. Storey E, du Sart D, Shaw JH, Lorentzos P, Kelly L, McKinley Gardner RJ, Forrest SM, Biros I, Nicholson GA: Frequency of spinocerebellar ataxia types 1, 2, 3, 6, and 7 in Australian patients with spinocerebellar ataxia. Am J Med Genet 2000, 95(4):351-357.

27. Saleem Q, Choudhry S, Mukerji M, Bashyam L, Padma MV, Chakravarthy A, Maheshwari MC, Jain S, Brahmachari SK: Molecular analysis of autosomal dominant hereditary ataxias in the Indian population: high frequency of SCA2 and evidence for a common founder mutation. Hum Genet 2000, 106(2):179-187.

28. Krishna N, Mohan S, Yashavantha BS, Rammurthy A, Kiran Kumar HB, Mittal U, Tyagi S, Mukerji M, Jain S, Pal PK, et al: SCA 1, SCA 2 \& SCA 3/ MJD mutations in ataxia syndromes in southern India. Indian J Med Res 2007, 126(5):465-470.

29. Bryer A, Krause A, Bill P, Davids V, Bryant D, Butler J, Heckmann J, Ramesar R, Greenberg J: The hereditary adult-onset ataxias in South Africa. J Neurol Sci 2003, 216(1):47-54.

30. Brusco A, Gellera C, Cagnoli C, Saluto A, Castucci A, Michielotto C, Fetoni V, Mariotti C, Migone N, Di Donato S, et al: Molecular genetics of hereditary spinocerebellar ataxia: mutation analysis of spinocerebellar ataxia genes and CAG/CTG repeat expansion detection in 225 Italian families. Arch Neurol 2004, 61(5):727-733.

31. Coutinho P: Doença de Machado-Joseph: Tentativa de definição. PhD Dissertation, Instituto de Ciências Biomédicas Abel Salazar, Porto; 1992.

32. Maciel P, Costa MC, Ferro A, Rousseau M, Santos CS, Gaspar C, Barros J, Rouleau GA, Coutinho P, Sequeiros J: Improvement in the molecular diagnosis of Machado-Joseph disease. Arch Neurol 2001, 58(11):1821-1827.

33. Bettencourt C, Santos C, Kay T, Vasconcelos J, Lima M: Analysis of segregation patterns in Machado-Joseph disease pedigrees. J Hum Genet 2008, 53(10):920-923

34. Lima L, Coutinho P: Clinical criteria for diagnosis of Machado-Joseph disease: report of a non-Azorena Portuguese family. Neurology 1980, 30(3):319-322.

35. Carvalho DR, La Rocque-Ferreira A, Rizzo IM, Imamura EU, Speck-Martins CE: Homozygosity enhances severity in spinocerebellar ataxia type 3. Pediatr Neurol 2008, 38(4):296-299.

36. Kieling C, Prestes PR, Saraiva-Pereira ML, Jardim LB: Survival estimates for patients with Machado-Joseph disease (SCA3). Clin Genet 2007, 72(6):543-545.

37. Suite ND, Sequeiros J, McKhann GM: Machado-Joseph disease in a Sicilian-American family. J Neurogenet 1986, 3(3):177-182.

38. Sakai T, Kawakami H: Machado-Joseph disease: A proposal of spastic paraplegic subtype. Neurology 1996, 46(3):846-847.

39. Iwabuchi K, Tsuchiya K, Uchihara T, Yagishita S: Autosomal dominant spinocerebellar degenerations. Clinical, pathological, and genetic correlations. Rev Neurol (Paris) 1999, 155(4):255-270.

40. Rub U, Brunt ER, Deller T: New insights into the pathoanatomy of spinocerebellar ataxia type 3 (Machado-Joseph disease). Curr Opin Neurol 2008, 21(2):111-116.

41. Yamada M, Sato T, Tsuji S, Takahashi H: CAG repeat disorder models and human neuropathology: similarities and differences. Acta Neuropathol 2008, 115(1):71-86.

42. Horimoto $Y$, Matsumoto M, Akatsu H, Kojima A, Yoshida M, Nokura K, Yuasa H, Katada E, Yamamoto T, Kosaka K, et al: Longitudinal study on MRI intensity changes of Machado-Joseph disease: correlation between MRI findings and neuropathological changes. J Neurol 2011.

43. Rub U, de Vos RA, Schultz C, Brunt ER, Paulson H, Braak H: Spinocerebellar ataxia type 3 (Machado-Joseph disease): severe destruction of the lateral reticular nucleus. Brain 2002, 125(Pt 9):2115-2124.

44. Rub U, Brunt ER, Gierga K, Schultz C, Paulson H, de Vos RA, Braak H: The nucleus raphe interpositus in spinocerebellar ataxia type 3 (MachadoJoseph disease). J Chem Neuroanat 2003, 25(2):115-127.

45. Yamada M, Tan CF, Inenaga C, Tsuji S, Takahashi H: Sharing of polyglutamine localization by the neuronal nucleus and cytoplasm in CAG-repeat diseases. Neuropathol Appl Neurobiol 2004, 30(6):665-675.

46. Spinocerebellar Ataxia Type 3. [http://www.ncbi.n/m.nih.gov/bookshelf/br. fcgi?book=gene\&part=sca3].
47. Eto K, Sumi SM, Bird TD, McEvoy-Bush T, Boehnke M, Schellenberg G: Family with dominantly inherited ataxia, amyotrophy, and peripheral sensory loss. Spinopontine atrophy or Machado-Joseph Azorean disease in another non-Portuguese family? Arch Neurol 1990, 47(9):968-974.

48. Sudarsky L, Coutinho P: Machado-Joseph disease. Clin Neurosci 1995, $3(1): 17-22$.

49. Durr A, Stevanin G, Cancel G, Duyckaerts C, Abbas N, Didierjean O, Chneiweiss H, Benomar A, Lyon-Caen O, Julien J, et al: Spinocerebellar ataxia 3 and Machado-Joseph disease: clinical, molecular, and neuropathological features. Ann Neurol 1996, 39(4):490-499.

50. Paulson HL, Das SS, Crino PB, Perez MK, Patel SC, Gotsdiner D, Fischbeck KH, Pittman RN: Machado-Joseph disease gene product is a cytoplasmic protein widely expressed in brain. Ann Neurol 1997, 41(4):453-462

51. Robitaille Y, Lopes-Cendes I, Becher M, Rouleau G, Clark AW: The neuropathology of CAG repeat diseases: review and update of genetic and molecular features. Brain Pathol 1997, 7(3):901-926.

52. Schmidt $T$, Landwehrmeyer GB, Schmitt I, Trottier $Y$, Auburger $G$, Laccone $F$, Klockgether T, Volpel M, Epplen JT, Schols $L$, et al: An isoform of ataxin-3 accumulates in the nucleus of neuronal cells in affected brain regions of SCA3 patients. Brain Pathol 1998, 8(4):669-679.

53. Gilman S: The spinocerebellar ataxias. Clin Neuropharmacol 2000 23(6):296-303.

54. Yamada M, Hayashi S, Tsuji S, Takahashi H: Involvement of the cerebral cortex and autonomic ganglia in Machado-Joseph disease. Acta Neuropathol 2001, 101(2):140-144.

55. Koeppen $\mathrm{AH}$ : The pathogenesis of spinocerebellar ataxia. Cerebellum 2005, 4(1):62-73.

56. Wang $Y G$, Du J, Wang JL, Chen J, Chen C, Luo YY, Xiao ZQ, Jiang $H$, Yan XX, Xia K, et al: Six cases of SCA3/MJD patients that mimic hereditary spastic paraplegia in clinic. J Neurol Sci 2009, 285(1-2):121-4, 15.

57. Imon Y, Katayama S, Kawakami H, Murata Y, Oka M, Nakamura S: A necropsied case of Machado-Joseph disease with a hyperintense signal of transverse pontine fibres on long TR sequences of magnetic resonance images. J Neurol Neurosurg Psychiatry 1998, 64(1):140-141.

58. Murata $Y$, Yamaguchi $S$, Kawakami H, Imon $Y$, Maruyama $H$, Sakai $T$, Kazuta T, Ohtake T, Nishimura M, Saida T, et al: Characteristic magnetic resonance imaging findings in Machado-Joseph disease. Arch Neurol 1998, 55(1):33-37.

59. Yamada S, Nishimiya J, Nakajima T, Taketazu F: Linear high intensity area along the medial margin of the internal segment of the globus pallidus in Machado-Joseph disease patients. J Neurol Neurosurg Psychiatry 2005, 76(4):573-575.

60. Lee YC, Liu CS, Wu HM, Wang PS, Chang MH, Soong BW: The 'hot cross bun' sign in the patients with spinocerebellar ataxia. Eur J Neurol 2009, 16(4):513-516.

61. De Oliveira MS, D’Abreu A, Franca MC Jr, Lopes-Cendes I, Cendes F, Castellano G: MRI-Texture Analysis of Corpus Callosum, Thalamus, Putamen, and Caudate in Machado-Joseph Disease. J Neuroimaging 2010.

62. Klockgether T, Skalej M, Wedekind D, Luft AR, Welte D, Schulz JB, Abele M, Burk K, Laccone F, Brice A, et al: Autosomal dominant cerebellar ataxia type I. MRI-based volumetry of posterior fossa structures and basal ganglia in spinocerebellar ataxia types 1, 2 and 3. Brain 1998, 121(Pt 9):1687-1693.

63. D'Abreu A, Franca M, Appenzeller S, Lopes-Cendes I, Cendes F: Axonal dysfunction in the deep white matter in Machado-Joseph disease. J Neuroimaging 2009, 19(1):9-12.

64. Takiyama Y, Nishizawa M, Tanaka H, Kawashima S, Sakamoto H, Karube Y, Shimazaki H, Soutome M, Endo K, Ohta S, et al: The gene for MachadoJoseph disease maps to human chromosome 14q. Nat Genet 1993, 4(3):300-304.

65. Kawaguchi Y, Okamoto T, Taniwaki M, Aizawa M, Inoue M, Katayama S, Kawakami H, Nakamura S, Nishimura M, Akiguchi I, et al: CAG expansions in a novel gene for Machado-Joseph disease at chromosome 14q32.1. Nat Genet 1994, 8(3):221-228.

66. Ichikawa Y, Goto J, Hattori M, Toyoda A, Ishii K, Jeong SY, Hashida H, Masuda N, Ogata K, Kasai F, et al: The genomic structure and expression of MJD, the Machado-Joseph disease gene. J Hum Genet 2001, 46(7):413-422.

67. Bettencourt C, Santos C, Montiel R, Costa MC, Cruz-Morales P, Santos LR, Simões N, Kay T, Vasconcelos J, Maciel P, et al: Increased transcript 
diversity: novel splicing variants of Machado-Joseph Disease gene (ATXN3). Neurogenetics 2010, 11(2):193-202.

68. Takiyama Y, Sakoe K, Nakano I, Nishizawa M: Machado-Joseph disease: cerebellar ataxia and autonomic dysfunction in a patient with the shortest known expanded allele (56 CAG repeat units) of the MJD1 gene. Neurology 1997, 49(2):604-606.

69. Quan F, Egan R, DB J, Popovich B: An unusually small 55 repeat MJD1 CAG allele in a patient with Machado-Joseph disease [abstract]. Am $J$ Hum Genet 1997, 61:A318.

70. van Schaik IN, Jobsis GJ, Vermeulen M, Keizers H, Bolhuis PA, de Visser M: Machado-Joseph disease presenting as severe asymmetric proximal neuropathy. J Neurol Neurosurg Psychiatry 1997, 63(4):534-536.

71. van Alfen N, Sinke RJ, Zwarts MJ, Gabreels-Festen A, Praamstra P, Kremer BP, Horstink MW: Intermediate CAG repeat lengths $(53,54)$ for MJD/SCA3 are associated with an abnormal phenotype. Ann Neurol 2001, 49(6):805-807.

72. Gu W, Ma H, Wang K, Jin M, Zhou Y, Liu X, Wang G, Shen Y: The shortest expanded allele of the MJD1 gene in a Chinese MJD kindred with autonomic dysfunction. Eur Neurol 2004, 52(2):107-111.

73. Padiath QS, Srivastava AK, Roy S, Jain S, Brahmachari SK: Identification of a novel 45 repeat unstable allele associated with a disease phenotype at the MJD1/SCA3 locus. Am J Med Genet B Neuropsychiatr Genet 2005, 133B(1):124-126

74. Walker FO: Huntington's disease. Lancet 2007, 369(9557):218-228.

75. Goto J, Watanabe M, Ichikawa Y, Yee SB, Ihara N, Endo K, Igarashi S, Takiyama Y, Gaspar C, Maciel P, et al: Machado-Joseph disease gene products carrying different carboxyl termini. Neurosci Res 1997, 28(4):373-377.

76. Alternative Splicing Prediction DataBase. [http://www.caspur.it/ASPicDB].

77. Gales L, Cortes L, Almeida C, Melo CV, do Carmo Costa M, Maciel P, Clarke DT, Damas AM, Macedo-Ribeiro S: Towards a structural understanding of the fibrillization pathway in Machado-Joseph's disease: trapping early oligomers of non-expanded ataxin-3. J Mol Biol 2005, 353(3):642-654.

78. Tzvetkov N, Breuer P: Josephin domain-containing proteins from a variety of species are active de-ubiquitination enzymes. Biol Chem 2007, 388(9):973-978.

79. Albrecht $\mathrm{M}$, Golatta $\mathrm{M}$, Wullner $\mathrm{U}$, Lengauer T: Structural and functional analysis of ataxin-2 and ataxin-3. Eur J Biochem 2004, 271(15):3155-3170

80. Riess O, Rub U, Pastore A, Bauer P, Schols L: SCA3: neurological features, pathogenesis and animal models. Cerebellum 2008, 7(2):125-137.

81. Nijman SM, Luna-Vargas MP, Velds A, Brummelkamp TR, Dirac AM Sixma TK, Bernards R: A genomic and functional inventory of deubiquitinating enzymes. Cell 2005, 123(5):773-786.

82. Todi SV, Winborn BJ, Scaglione KM, Blount JR, Travis SM, Paulson HL: Ubiquitination directly enhances activity of the deubiquitinating enzyme ataxin-3. EMBO J 2009, 28(4):372-382.

83. Ferro A, Carvalho AL, Teixeira-Castro A, Almeida C, Tome RJ, Cortes L, Rodrigues AJ, Logarinho E, Sequeiros J, Macedo-Ribeiro S, et al: NEDD8: a new ataxin-3 interactor. Biochim Biophys Acta 2007, 1773(11):1619-1627.

84. Li F, Macfarlan T, Pittman RN, Chakravarti D: Ataxin-3 is a histone-binding protein with two independent transcriptional corepressor activities. $J$ Biol Chem 2002, 277(47):45004-45012.

85. Burnett $B G$, Pittman RN: The polyglutamine neurodegenerative protein ataxin 3 regulates aggresome formation. Proc Natl Acad Sci USA 2005, 102(12):4330-4335

86. Rodrigues AJ, do Carmo Costa M, Silva TL, Ferreira D, Bajanca F, Logarinho E, Maciel P: Absence of ataxin-3 leads to cytoskeletal disorganization and increased cell death. Biochim Biophys Acta 1803(10):1154-1163.

87. do Carmo Costa M, Bajanca F, Rodrigues AJ, Tome RJ, Corthals G, MacedoRibeiro S, Paulson HL, Logarinho E, Maciel P: Ataxin-3 plays a role in mouse myogenic differentiation through regulation of integrin subunit levels. PLoS One 5(7):e11728.

88. Mauri PL, Riva M, Ambu D, De Palma A, Secundo F, Benazzi L, Valtorta M, Tortora P, Fusi P: Ataxin-3 is subject to autolytic cleavage. FEBS J 2006, 273(18):4277-4286

89. Paulson HL, Perez MK, Trottier Y, Trojanowski JQ, Subramony SH, Das SS, Vig P, Mandel JL, Fischbeck KH, Pittman RN: Intranuclear inclusions of expanded polyglutamine protein in spinocerebellar ataxia type 3. Neuron 1997, 19(2):333-344.
90. Schmidt T, Lindenberg KS, Krebs A, Schols L, Laccone F, Herms J, Rechsteiner M, Riess O, Landwehrmeyer GB: Protein surveillance machinery in brains with spinocerebellar ataxia type 3: redistribution and differential recruitment of 265 proteasome subunits and chaperones to neuronal intranuclear inclusions. Ann Neurol 2002, 51(3):302-310.

91. Evert BO, Schelhaas J, Fleischer H, de Vos RA, Brunt ER, Stenzel W, Klockgether T, Wullner U: Neuronal intranuclear inclusions, dysregulation of cytokine expression and cell death in spinocerebellar ataxia type 3 . Clin Neuropathol 2006, 25(6):272-281.

92. Rub U, de Vos RA, Brunt ER, Sebesteny T, Schols L, Auburger G, Bohl J, Ghebremedhin E, Gierga K, Seidel K, et al: Spinocerebellar ataxia type 3 (SCA3): thalamic neurodegeneration occurs independently from thalamic ataxin-3 immunopositive neuronal intranuclear inclusions. Brain Pathol 2006, 16(3):218-227.

93. Gaspar C, Lopes-Cendes I, Hayes S, Goto J, Arvidsson K, Dias A, Silveira I, Maciel P, Coutinho P, Lima M, et al: Ancestral origins of the MachadoJoseph disease mutation: a worldwide haplotype study. Am J Hum Genet 2001, 68(2):523-528.

94. Martins S, Calafell F, Gaspar C, Wong VC, Silveira I, Nicholson GA, Brunt ER, Tranebjaerg L, Stevanin G, Hsieh M, et al: Asian origin for the worldwidespread mutational event in Machado-Joseph disease. Arch Neurol 2007, 64(10):1502-1508.

95. Lima M: Doença de Machado-Joseph nos Açores: Estudo epidemiológico, biodemográfico e genético. Ponta Delgada: University of the Azores; 1996.

96. Lima M, Mayer FM, Coutinho P, Abade A: Origins of a mutation: population genetics of Machado-Joseph disease in the Azores (Portugal). Hum Biol 1998, 70(6):1011-1023.

97. Bettencourt C, Silva-Fernandes A, Montiel R, Santos C, Maciel P, Lima M: Triplet Repeats: Features, Dynamics and Evolutionary Mechanisms. In Recent Advances in Molecular Biology and Evolution: Applications to Biological Anthropology. Edited by: Santos C, Lima M. Kerala: Research Signpost; 2007:83-114.

98. Lima M, Costa MC, Montiel R, Ferro A, Santos C, Silva C, Bettencourt C, Sousa A, Sequeiros J, Coutinho P, et al: Population genetics of wild-type CAG repeats in the Machado-Joseph disease gene in Portugal. Hum Hered 2005, 60(3):156-163.

99. Martins S, Calafell F, Wong VC, Sequeiros J, Amorim A: A multistep mutation mechanism drives the evolution of the CAG repeat at MJD/ SCA3 locus. Eur J Hum Genet 2006, 14(8):932-940.

100. Sequeiros J: Análise genética da variação fenotípica na doença de Machado-Joseph. PhD Dissertation. Instituto de Ciências Biomédicas de Abel Salazar, Universidade do Porto; 1989.

101. Maciel P, Gaspar C, DeStefano AL, Silveira I, Coutinho P, Radvany J, Dawson DM, Sudarsky L, Guimaraes J, Loureiro JE, et al: Correlation between CAG repeat length and clinical features in Machado-Joseph disease. Am J Hum Genet 1995, 57(1):54-61.

102. Maruyama H, Nakamura S, Matsuyama Z, Sakai T, Doyu M, Sobue G, Seto M, Tsujihata M, Oh-i T, Nishio T, et al: Molecular features of the CAG repeats and clinical manifestation of Machado-Joseph disease. Hum Mol Genet 1995, 4(5):807-812

103. Bettencourt C, Santos C, Montiel R, Kay T, Vasconcelos J, Maciel P, Lima M: The (CAG)(n) tract of Machado-Joseph Disease gene (ATXN3): a comparison between DNA and mRNA in patients and controls. Eur $\rfloor$ Hum Genet 2009.

104. Takiyama Y, Igarashi S, Rogaeva EA, Endo K, Rogaev El, Tanaka H, Sherrington R, Sanpei K, Liang Y, Saito M, et al: Evidence for intergenerational instability in the CAG repeat in the MJD1 gene and for conserved haplotypes at flanking markers amongst Japanese and Caucasian subjects with Machado-Joseph disease. Hum Mol Genet 1995, 4(7):1137-1146.

105. Lerer I, Merims D, Abeliovich D, Zlotogora J, Gadoth N: Machado-Joseph disease: correlation between the clinical features, the CAG repeat length and homozygosity for the mutation. Eur J Hum Genet 1996, 4(1):3-7.

106. Sobue G, Doyu M, Nakao N, Shimada N, Mitsuma T, Maruyama H, Kawakami S, Nakamura S: Homozygosity for Machado-Joseph disease gene enhances phenotypic severity. I Neurol Neurosurg Psychiatry 1996, 60(3):354-356.

107. Tsuji S: Molecular genetics of triplet repeats: unstable expansion of triplet repeats as a new mechanism for neurodegenerative diseases. Intern Med 1997, 36(1):3-8. 
108. Bettencourt C, Fialho RN, Santos C, Montiel R, Bruges-Armas J, Maciel P, Lima M: Segregation distortion of wild-type alleles at the MachadoJoseph disease locus: a study in normal families from the Azores islands (Portugal). J Hum Genet 2008, 53(4):333-339.

109. Igarashi S, Takiyama Y, Cancel G, Rogaeva EA, Sasaki H, Wakisaka A, Zhou YX, Takano H, Endo K, Sanpei K, et al: Intergenerational instability of the CAG repeat of the gene for Machado-Joseph disease (MJD1) is affected by the genotype of the normal chromosome: implications for the molecular mechanisms of the instability of the CAG repeat. Hum Mol Genet 1996, 5(7):923-932

110. DeStefano AL, Cupples LA, Maciel P, Gaspar C, Radvany J, Dawson DM, Sudarsky L, Corwin L, Coutinho P, MacLeod P, et al: A familial factor independent of CAG repeat length influences age at onset of MachadoJoseph disease. Am J Hum Genet 1996, 59(1):119-127.

111. van de Warrenburg BP, Hendriks $H$, Durr A, van Zuijlen MC, Stevanin G, Camuzat A, Sinke RJ, Brice A, Kremer BP: Age at onset variance analysis in spinocerebellar ataxias: a study in a Dutch-French cohort. Ann Neurol 2005, 57(4):505-512.

112. Jardim L, Silveira I, Pereira ML, do Ceu Moreira M, Mendonca P, Sequeiros J, Giugliani R: Searching for modulating effects of SCA2, SCA6 and DRPLA CAG tracts on the Machado-Joseph disease (SCA3) phenotype. Acto Neurol Scand 2003, 107(3):211-214.

113. Lopes-Cendes I, Silveira I, Maciel P, Gaspar C, Radvany J, Chitayat D, Babul R, Stewart J, Dolliver M, Robitaille $Y$, et al: Limits of clinical assessment in the accurate diagnosis of Machado-Joseph disease. Arch Neurol 1996, 53(11):1168-1174.

114. Sequeiros J, Maciel P, Taborda F, Ledo S, Rocha JC, Lopes A, Reto F, Fortuna AM, Rousseau M, Fleming $M$, et al: Prenatal diagnosis of Machado-Joseph disease by direct mutation analysis. Prenat Diagn 1998, 18(6):611-617.

115. Drusedau M, Dreesen JC, De Die-Smulders C, Hardy K, Bras M, Dumoulin JC, Evers JL, Smeets HJ, Geraedts JP, Herbergs J: Preimplantation genetic diagnosis of spinocerebellar ataxia 3 by $(C A G)(n)$ repeat detection. $\mathrm{Mol}$ Hum Reprod 2004, 10(1):71-75.

116. Gonzalez C, Lima M, Kay T, Silva C, Santos C, Santos J: Short-term psychological impact of predictive testing for Machado-Joseph disease: depression and anxiety levels in individuals at risk from the Azores (Portugal). Community Genet 2004, 7(4):196-201.

117. Paul C, Martin I, do Rosario Silva M, Silva M, Coutinho P, Sequeiros J: Living with Machado-Joseph disease in a small rural community of the Tagus valley. Community Genet 1999, 2(4):190-195

118. Sequeiros J: General Protocol of the National Program of Predictive Testing and Genetic Counselling in Machado-Joseph disease. In Predictive Testing in Machado-Joseph Disease (in Portuguese). Edited by: Sequeiros J. Porto: UnIGENe-IBMC; 1996

119. Lima M, Kay T, Vasconcelos J, Mota-Vieira L, Gonzalez C, Peixoto A, Abade A, MacLeod P, Graca R, Santos J: Disease knowledge and attitudes toward predictive testing and prenatal diagnosis in families with Machado-Joseph disease from the Azores Islands (Portugal). Community Genet 2001, 4(1):36-42

120. Leite A, Paúl C, Sequeiros J: O bem-estar psicológico em individuos de risco para doenças neurológicas hereditárias de aparecimento tardio e controlos [article in Portuguese]. Psicologia, Saúde \& Doença 2002, 3(4):113-118

121. Rolim L, Leite A, Ledo S, Paneque M, Sequeiros J, Fleming M: Psychological aspects of pre-symptomatic testing for Machado-Joseph disease and familial amyloid polyneuropathy type I. Clin Genet 2006, 69(4):297-305.

122. Abe K, Itoyama Y: Psychological consequences of genetic testing for spinocerebellar ataxia in the Japanese. European Journal of Neurology 1997, 4:593-600

123. Smith CO, Lipe HP, Bird TD: Impact of presymptomatic genetic testing for hereditary ataxia and neuromuscular disorders. Arch Neurol 2004, 61(6):875-880

124. Cancel G, Gourfinkel-An I, Stevanin G, Didierjean O, Abbas N, Hirsch E, Agid $Y$, Brice A: Somatic mosaicism of the CAG repeat expansion in spinocerebellar ataxia type 3/Machado-Joseph disease. Hum Mutat 1998, 11(1):23-27.

125. Ogawa M: Pharmacological treatments of cerebellar ataxia. Cerebellum 2004, 3(2):107-111
126. Correia M, Coutinho P, Silva MC, Guimaraes J, Amado J, Matos E: Evaluation of the effect of sulphametoxazole and trimethoprim in patients with Machado-Joseph disease. Rev Neurol 1995, 23(121):632-634.

127. Tuite PJ, Rogaeva EA, St George-Hyslop PH, Lang AE: Dopa-responsive parkinsonism phenotype of Machado-Joseph disease: confirmation of 14q CAG expansion. Ann Neurol 1995, 38(4):684-687.

128. Buhmann C, Bussopulos A, Oechsner M: Dopaminergic response in Parkinsonian phenotype of Machado-Joseph disease. Mov Disord 2003, 18(2):219-221.

129. Wilder-Smith E, Tan EK, Law HY, Zhao Y, Ng I, Wong MC: Spinocerebellar ataxia type 3 presenting as an L-DOPA responsive dystonia phenotype in a Chinese family. J Neurol Sci 2003, 213(1-2):25-28.

130. Nandagopal R, Moorthy SG: Dramatic levodopa responsiveness of dystonia in a sporadic case of spinocerebellar ataxia type 3. Postgrad Med J 2004, 80(944):363-365.

131. Kanai K, Kuwabara S, Arai K, Sung JY, Ogawara K, Hattori T: Muscle cramp in Machado-Joseph disease: altered motor axonal excitability properties and mexiletine treatment. Brain 2003, 126(Pt 4):965-973.

132. Mello KA, Abbott BP: Effect of sulfamethoxazole and trimethoprim on neurologic dysfunction in a patient with Joseph's disease. Arch Neuro 1988, 45(2):210-213

133. Azulay JP, Blin O, Mestre D, Sangla I, Serratrice G: Contrast sensitivity improvement with sulfamethoxazole and trimethoprim in a patient with Machado-Joseph disease without spasticity. J Neurol Sci 1994, 123(12):95-99.

134. Sakai T, Matsuishi T, Yamada S, Komori H, Iwashita H: Sulfamethoxazoletrimethoprim double-blind, placebo-controlled, crossover trial in Machado-Joseph disease: sulfamethoxazole-trimethoprim increases cerebrospinal fluid level of biopterin. J Neural Transm Gen Sect 1995, 102(2):159-172.

135. Schulte T, Mattern R, Berger K, Szymanski S, Klotz P, Kraus PH, Przuntek H, Schols L: Double-blind crossover trial of trimethoprim-sulfamethoxazole in spinocerebellar ataxia type 3/Machado-Joseph disease. Arch Neurol 2001, 58(9):1451-1457.

136. Monte TL, Rieder CR, Tort AB, Rockenback I, Pereira ML, Silveira I, Ferro A, Sequeiros J, Jardim LB: Use of fluoxetine for treatment of MachadoJoseph disease: an open-label study. Acta Neurol Scand 2003, 107(3):207-210.

137. Shirasaki H, Ishida C, Nakajima T, Kamei H, Koide T, Fukuhara N: [A quantitative evaluation of spinocerebellar degeneration by an acoustic analysis-the effect of taltirelin hydrate on patients with MachadoJoseph disease]. Rinsho Shinkeigaku 2003, 43(4):143-148.

138. Takei A, Fukazawa T, Hamada T, Sohma H, Yabe I, Sasaki H, Tashiro K: Effects of tandospirone on "5-HT1A receptor-associated symptoms" in patients with Machado-Josephe disease: an open-label study. Clin Neuropharmacol 2004, 27(1):9-13.

139. Liu CS, Hsu HM, Cheng WL, Hsieh M: Clinical and molecular events in patients with Machado-Joseph disease under lamotrigine therapy. Acta Neurol Scand 2005, 111(6):385-390.

140. Underwood BR, Rubinsztein DC: Spinocerebellar ataxias caused by polyglutamine expansions: a review of therapeutic strategies. Cerebellum 2008, 7(2):215-221.

141. D'Abreu A, Franca MC, Paulson HL, Lopes-Cendes I: Caring for MachadoJoseph disease: current understanding and how to help patients. Parkinsonism Relat Disord 2010, 16(1):2-7.

142. Schmitt I, Linden $M$, Khazneh $H$, Evert BO, Breuer $P$, Klockgether $T$ Wuellner U: Inactivation of the mouse Atxn3 (ataxin-3) gene increases protein ubiquitination. Biochem Biophys Res Commun 2007, 362(3):734-739.

143. Rodrigues AJ, Coppola G, Santos C, Costa Mdo C, Ailion M, Sequeiros J, Geschwind DH, Maciel P: Functional genomics and biochemical characterization of the C. elegans orthologue of the Machado-Joseph disease protein ataxin-3. FASEB J 2007, 21(4):1126-1136.

144. Miller VM, Xia H, Marrs GL, Gouvion CM, Lee G, Davidson BL, Paulson HL: Allele-specific silencing of dominant disease genes. Proc Natl Acad Sci USA 2003, 100(12):7195-7200

145. Alves S, Nascimento-Ferreira I, Auregan G, Hassig R, Dufour N, Brouillet E, Pedroso de Lima MC, Hantraye P, Pereira de Almeida L, Deglon N: Allelespecific RNA silencing of mutant ataxin-3 mediates neuroprotection in a rat model of Machado-Joseph disease. PLoS One 2008, 3(10):e3341. 
146. Hu J, Matsui M, Gagnon KT, Schwartz JC, Gabillet S, Arar K, Wu J, Bezprozvanny I, Corey DR: Allele-specific silencing of mutant huntingtin and ataxin-3 genes by targeting expanded CAG repeats in mRNAs. Nat Biotechnol 2009, 27(5):478-484.

doi:10.1186/1750-1172-6-35

Cite this article as: Bettencourt and Lima: Machado-Joseph Disease: from first descriptions to new perspectives. Orphanet Journal of Rare Diseases 2011 6:35.

Submit your next manuscript to BioMed Central and take full advantage of:

- Convenient online submission

- Thorough peer review

- No space constraints or color figure charges

- Immediate publication on acceptance

- Inclusion in PubMed, CAS, Scopus and Google Scholar

- Research which is freely available for redistribution

Submit your manuscript at www.biomedcentral.com/submit 